\title{
Systematic approach to design builds for freeform façade: AFA Cultural Center
}

\section{SIGRADI2018 TECHNOPOLITICAS \\ xxii congresso da sociedade iberoamericana de gráfica digital 22th conference of the iberoamerican society of digital graphics 07|08|09|novembro|2018 iau usp | são carlos | sp br}

\author{
Begüm Aktaş \\ Istanbul Altınbaş University| Istanbul Technical University | Turkey | \\ begum.aktas@altinbas.edu.tr \\ M. Birgül Çolakoğlu \\ Istanbul Technical University | Turkey | bigi@alum.mit.edu
}

\begin{abstract}
The design and construction of the complex, irregularly shaped, and curvilinear building forms are also known as freeform architecture, have gained an interest form architects and engineers. This paper presents how freeform façade designs are defined with its curvilinear geometric characteristics and the systematic approach that is used to design and implement them. The proposed method incorporates product design and integral façade construction approach at AFA Cultural Center freeform façade implementation. Therefore, the paper aims to improve the viability of the proposed method and decreasing the gap between the other disciplines and architects in a systematic way without losing the creativity of the architects.
\end{abstract}

Keywords: Parametric modeling; Systematic approach; Design thinking; System thinking; Freeform façade design.

\section{INTRODUCTION}

In the contemporary architecture, the design and construction of the complex, irregularly shaped and curvilinear building forms are also known as freeform architecture, have gained an interest from architects. A widely use of the computer-aided tools in contemporary architecture has created an influential new architectural language of curved surfaces, nonrepeating parts, freeform designs, digital analysis, and CAD/CAM fabrication as freeform architectural design. Nowadays, freeform architectural designs are still popular among designers and architects, and it is still difficult to find the proper geometrical definition of freeform. Computers have no longer been used only for drawing plans, sections, and elevations also they have been used as part of the digital fabrication and optimization process. Despite the developments in CAD/CAM, freeform architecture is still one of the major challenges for architects, engineers, and the building industry.

The freeform architectural designs owe their existence to the introduction of advanced digital design and manufacturing technologies. As a result of these technological developments particularly as a consequence of mass customization in architecture many successful freeform designs such as Guggenheim Museum Bilbao, the Walt Disney Concert Hall, Hayder Aliyev Cultural Center, Kunsthaus Contemporary Museum have been designed and constructed.

\section{SYSTEMATIC APPROACH TO DESIGN- BUILD}

In the modern era, standardization as a result of mass production was accepted as a necessary component for the progression of architecture, as Le Corbusier stated that "architecture is governed by standards." But, over the years, standard and repetitive mass-produced building components did not provide solutions for non-standard architectural designs and they limited the capacity of designers to respond with accuracy to the diverse variables that characterize their environment particularly for freeform designs. Before the implementation of digitalization as CAD/CAM tools, design and manufacturing process were a direct consequence of industrial manufacturing, the logic of mass production, and standardization. In the age of digitalization, computers have allowed architects to explore the design process in 3D rather than being restrained by the means of a drawing board and a standard design and manufacturing techniques and doing with the notions of mass productions. The advent of digitalization in design and manufacturing process enable mass customizations for designers and architects as powerful tools that can comfort the re-integration and help to produce novel, nonrepetitive building components, and assemblies.

Together with the digitalization in the design field, the emergence of the new construction methods and materials in the building technology, building elements separated mainly as load bearing and non-load bearing elements as a consequence of the mass production of steel, reinforced concrete, and glass in architecture designs as is façade design approach. "The historical position of mass production as one of the dominant factors of architectural "progress" requires rethinking." (Mostafavi \& Leatherbarrow, 2002). Façades are started to be accepted as reflections depending on construction and material improvements as well as interplaying between functional requirements and architectural design aspects. Façades are not only significant building elements as in aesthetical and performative aspects but also a system that complements building organization in association with the context of a surrounding.

Façades have become more important for functionality, performance, and user comfort of buildings as being an 
interface between interior and exterior conditions, as is an architectural appearance of buildings. With the increasing demands in design, construction, and technology as are energy efficiency, sustainability, user convenience, and aesthetic, building façades as shells turn into more complex designs. As a result of complex systems of building, shells could cause budget exceeding and a loss of time. "Therefore, architects try to exert influence on the system products to realize their designs." (Knaack, Klein, Bilow, \& Auer, 2014). Although utilizing systemized solutions has advantages to decrease the cost and time, the complex architectural design requires specific requirement and a high degree of knowledge for the solutions. Since the beginning of the freeform façade design, façade shell has turned into a multifunctional component of a building consisting of thermal, acoustic, waterproof, fire-protection, and ventilation functionalities of façade within complex multilayered systems. As a consequence of being a multifunctional component, close collaboration between various disciplines like architects, engineers, façade consultant, and a client has been required. Within this context, a systematic design approach came into prominence in the freeform design methodology.

With the precise knowledge of materials, construction, and fabrication techniques, systematic design approach has gained importance in the design process to take control of on the whole process. Beyond that, architects started to lead the entire design process from the early phase in collaboration with engineers, manufactures, and clients instead of passing their freeform façade designs to structural engineers or façade developers. Utilization of the computer to design process, a systematic design approach became apparent crucial key element within entire collaborations of design depending on the complex and challenging freeform design. Following a systematic design approach step by step to reach intended design result; in the analytical phase whole design requirements and goals should be listed, and then in the creative phase defined problems should be decomposed to sub-problems to find solutions to whole individual sub-problems to individual sub-solutions, and in the executive phase combining whole sub-solutions to overall solution as the whole system (Figure 1). Until achieving the requirements and goals of the design, designers, architects should iteratively move up and down between phases of the process. In the aim of the paper, the importance of the systematic design approach is defined as a guideline for freeform façade implementation by the way of a case study of façade design process of AFA Cultural Center.

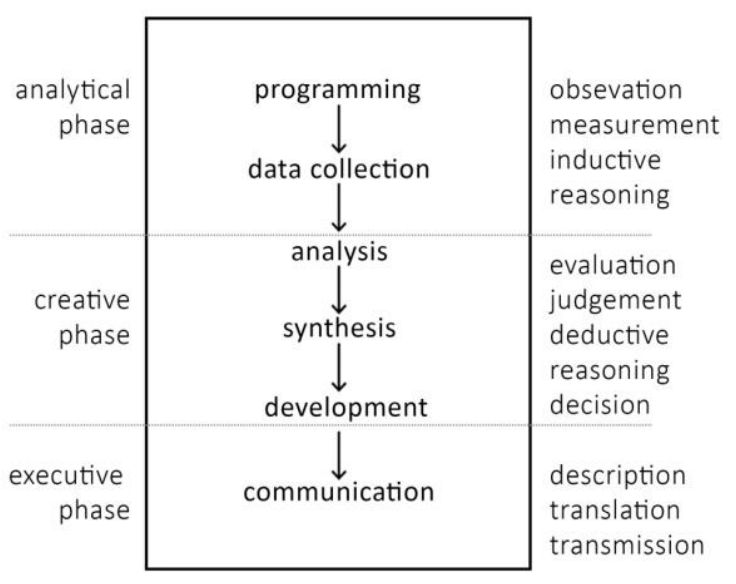

Figure 1: Bruce Archer's Systematic Design Approach (Council, 2007)

\section{CASE STUDY: AFA CULTURAL CENTER}

The cultural center hosts a wide entrance foyer that connects exhibition event and theatres for 1000 people and for 450 people, a café, offices, and car parking in Sakarya, Turkey (Figure 2). The AFA Cultural Center façade is designed as a shell façade with all elevations and roof as a whole as an integral façade system. The roof of the building was the fifth facet of the building as a shell. All shell system of the AFA Cultural Center was designed as an integral façade system. Façade consists of different functional and material features. The façade surface is firstly zoned according to geometrical properties then material properties as glass fin supported façade, metal sun shading system, and GRC panels (Figure 3).

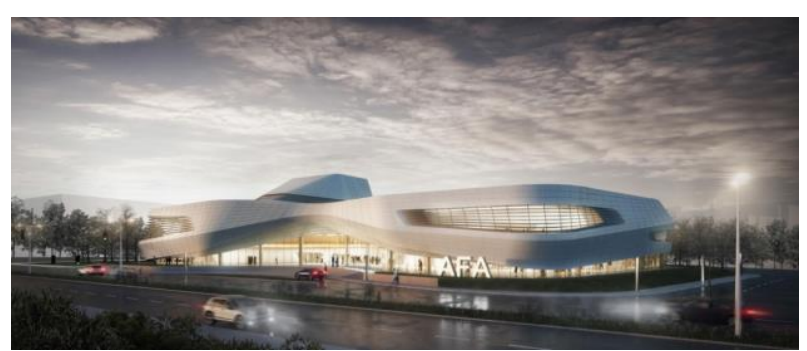

Figure 2: AFA Cultural Center by Melike Altınışık Architects, 2016. Source: Authors.

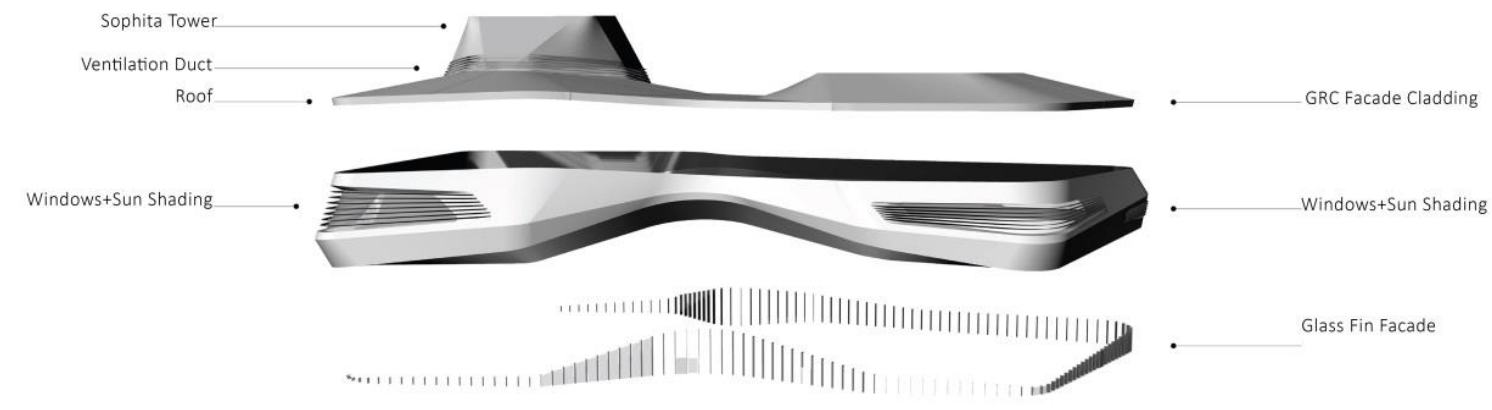

Figure 3: Façade zones according to material features. Source: Authors. 
In order to determine the requirements and goals of the façade design of AFA Cultural Center and construction details, a detailed diagram of the façade functions is drawn in figure 4 . The functions of the façade are divided into two main categories as exterior conditions and interior

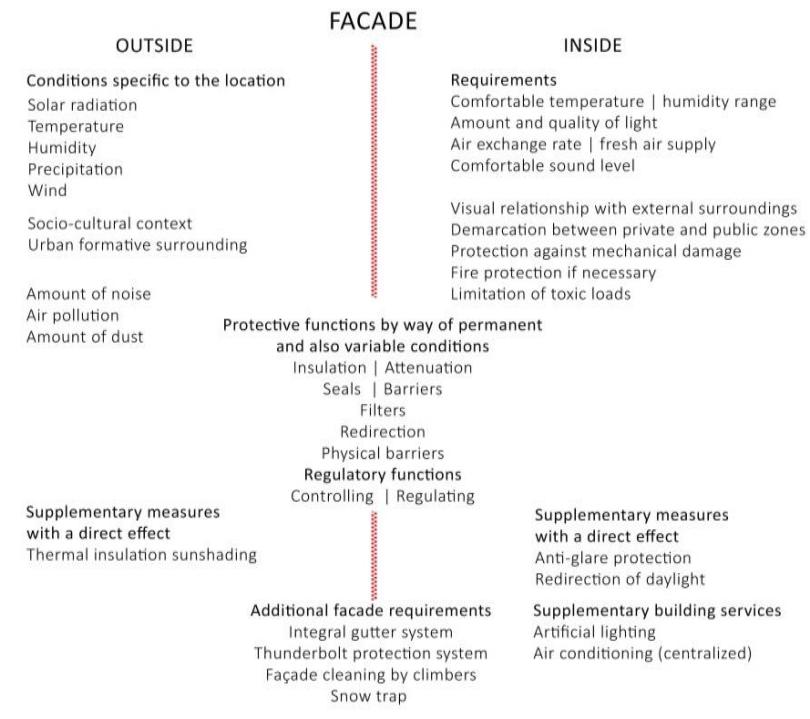

Figure 4: Functions of façade of AFA Cultural Center.Source: Authors.

categories. First deals with solar radiation, wind, and amount of noise. Second, with physical conditions of space that are functionality, the performance of the building as well as user comfort. Depending on the form of the AFA Cultural Center façade, additional requirements are needed such as façade cleaning systems provided by climbers; the integral gutter system which is located between secondary structure of the façade and primary structure of the façade; snow traps for statically calculations and also, thunderbolt protection system which protect building from thunderbolt and allows for changeability of GRC panels in case of damage on panels.

In the context of this paper, the façade is designed as the relation of the sub-systems within the integration of the building systems. AFA Cultural Center project was defined as integration among building components, subsystems, and material properties. With the support of the "building design specialist consulting" (bds) firm, most design decisions were taken together in a close collaboration with whole stakeholders to deal with the freeform façade surface and relationship within whole building systems as are façade-structure integration or façade services integration. In the collaboration with other disciplines, façade-structure integration, façade-services integration such as fresh air supply zones to the centralized ventilation system, layers of insulations, barriers, and filters are arranged in the one-meter thick zone. More importantly, in the borders of one-meter thickness, GRC panel structure connection is developed with the ability of three axes movability to help assembly process by bds consulting. Within this collaboration, the first design decision was to consider façade as a one-meter thick façade system which in section consists of GRC panel, the substructure of the GRC panel, galvanized steel hot section, waterproof membrane, heat insulation, vapor barrier, and trapeze sectioned structural galvanized steel deck as shown in figure 5 .

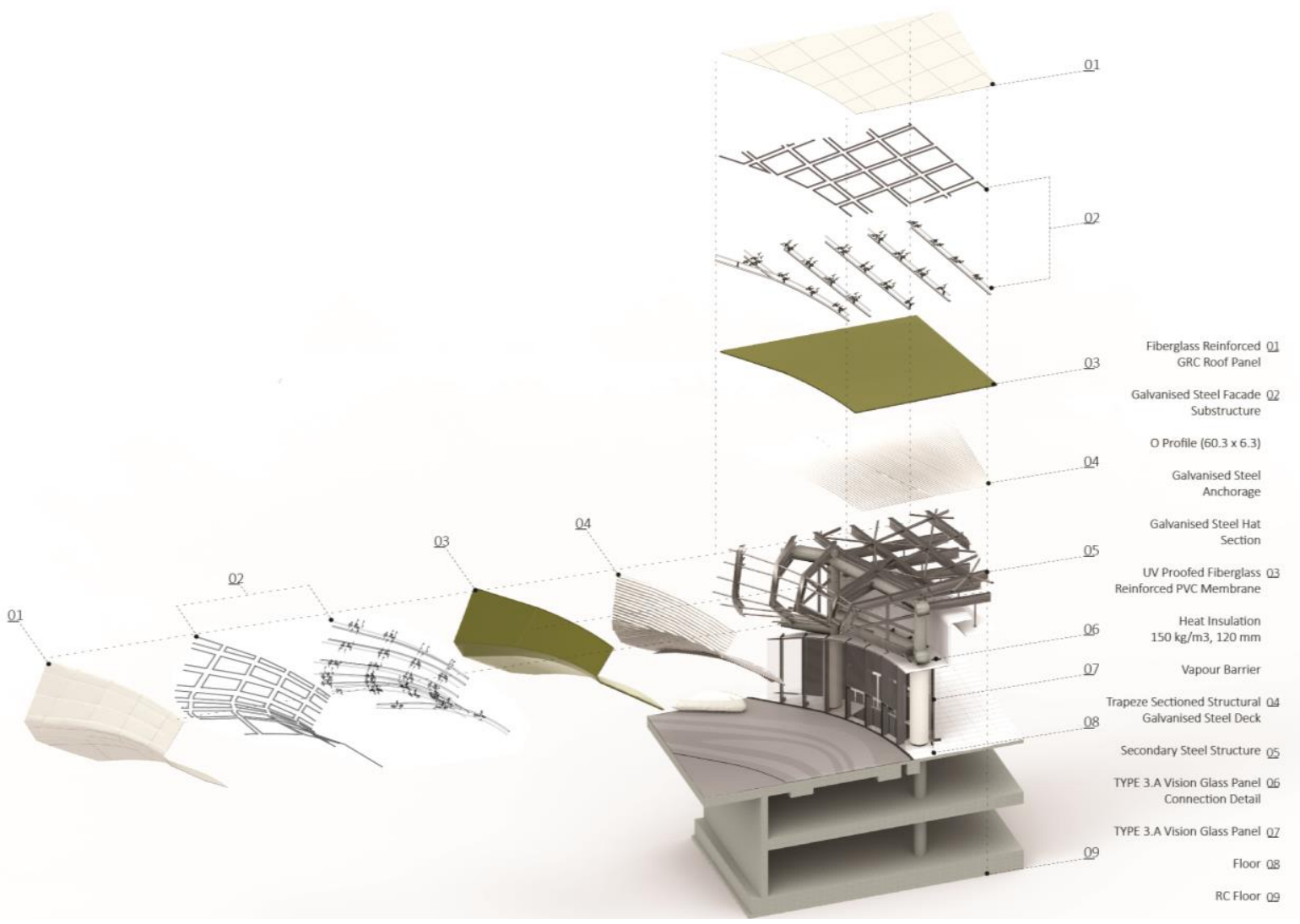

Figure 5: Detail of the one-meter thickness of the façade (By "Melike Altınışık Architects"). 


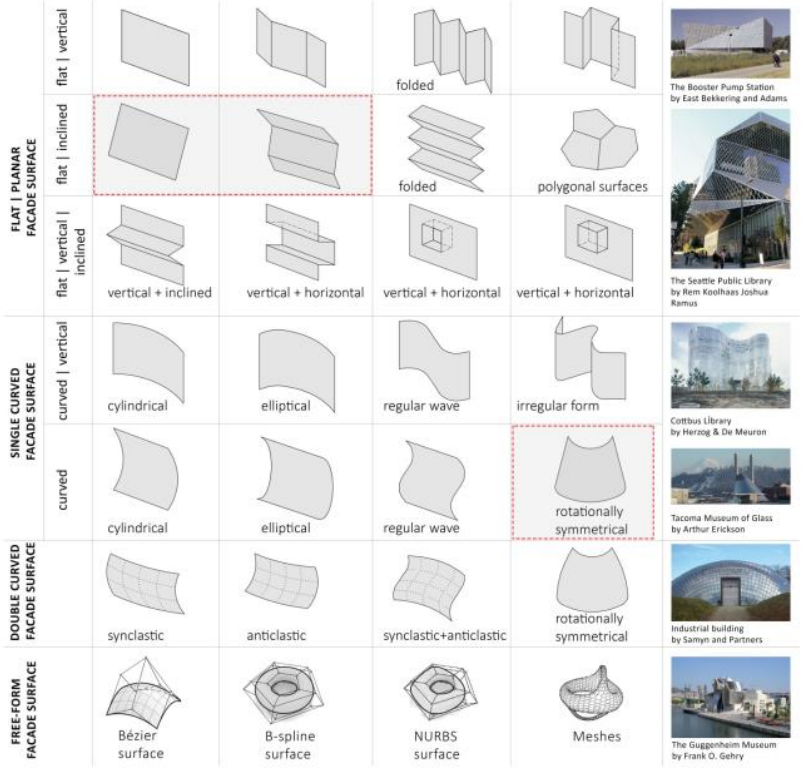

Figure 6: The classification of surface geometries. Source: Authors.

Geometry has always had an important place in architectural design as a design language particularly in freeform geometries. The façade of the AFA Cultural Center was designed as freeform consisting of planar and single curved surface geometries. In the current construction industry, in order to achieve the intended architectural appearance of the building, the façade was zoned into planar and single curved surfaces which are conically developable surfaces. As seen in figure 6, the red box indicates the geometric properties of the classification of the surfaces of the AFA Cultural Center. In the manufacturing process, planar and single curved surfaces are going to be manufactured independently from each other because of the manufacturing techniques of the GRC panels. The industrial production of the prefabricated GRC elements is manufactured by the mold. Each paneled surface requires a mold. In order to ease the manufacturing process and reducing the cost; façade surfaces are zoned according to geometric properties of the surface. After the manufacturing of the prefabricated GRC panels, they are transferred to the construction site for the assembly.

The main geometric principle of the reference curves is to round the perpendicular curve connections like as an arc. These arcs were defined by three points, and straight lines were defined by two points (Figure 7). Thus, one of the closed curves was designed as linkages of the threepoint arc-straight line-three-point arc-straight line connection until being the closed curve (Figure 8 ). The whole façade surface was defined by six closed curved named as curve $A$, curve $B$..

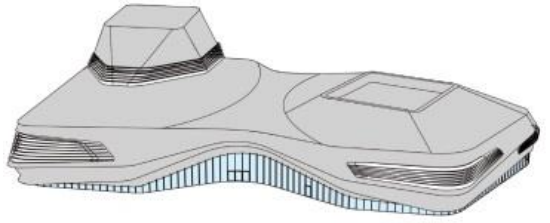

Mass Mode

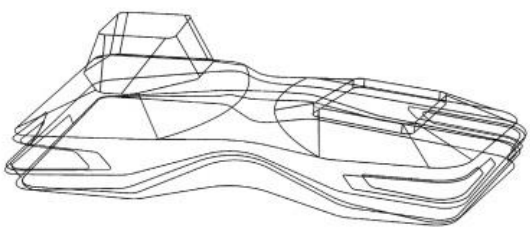

Wireframe Model

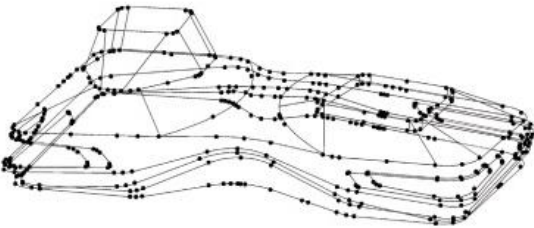

Point Cloud Model

Figure 7: Evolving of models from mass model to point cloud model. Source: Authors.

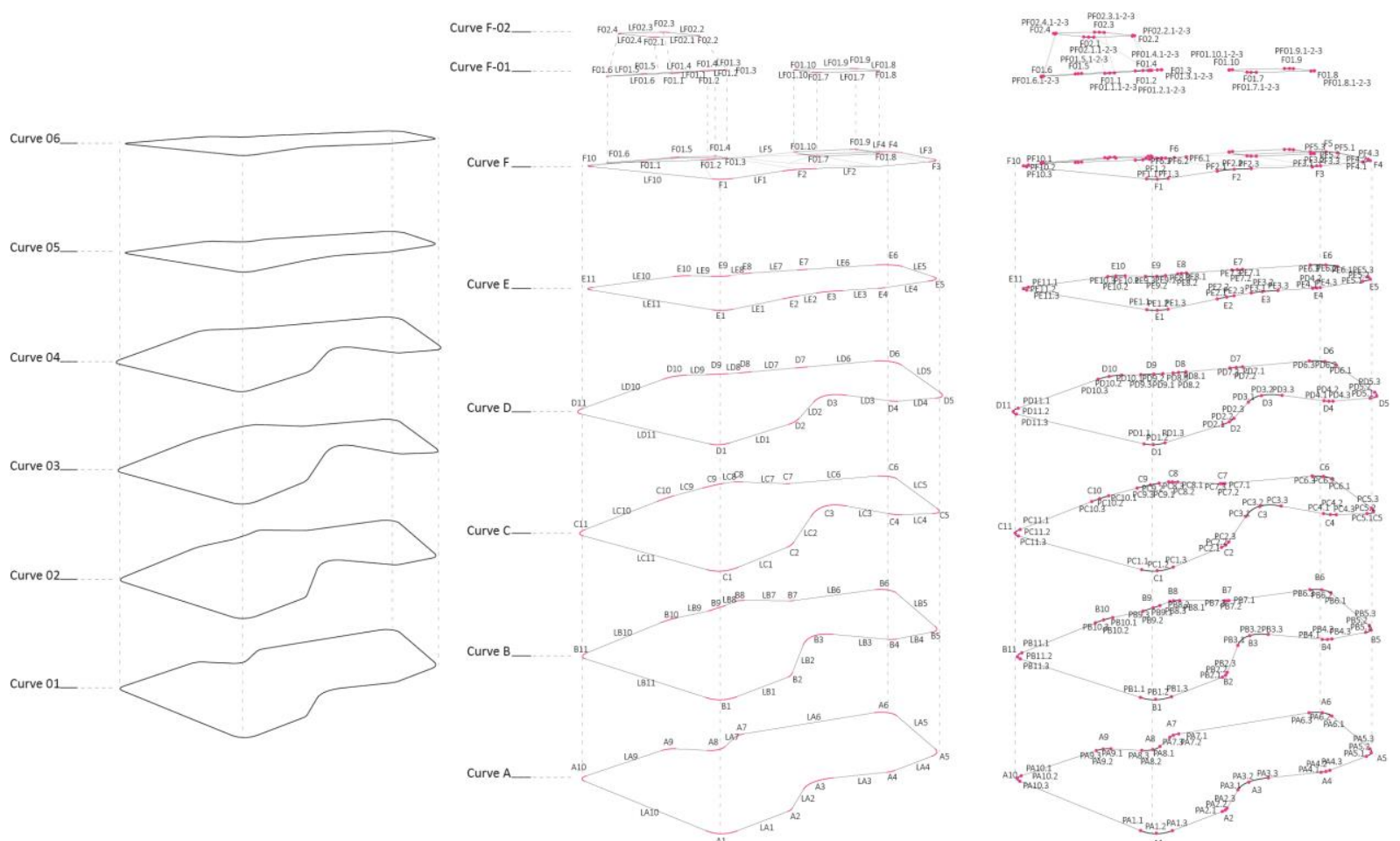

Figure 8: The reference curves and points of the façade sưface (By "Melike Altınışık Architects"). S'ource: Authors. 


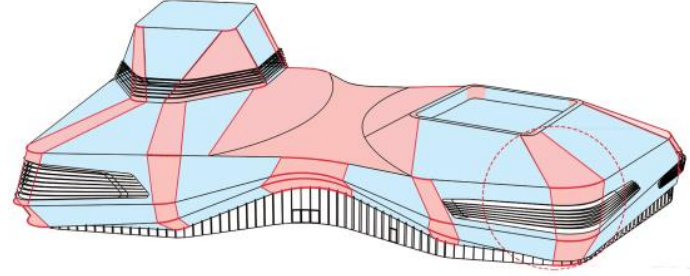

Planar Surfaces

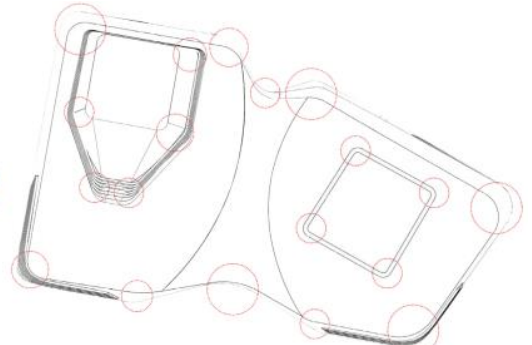

Conically Developable Surfaces

Figure 9: Façade zones according to single curved and planar surfaces. Source: Authors.

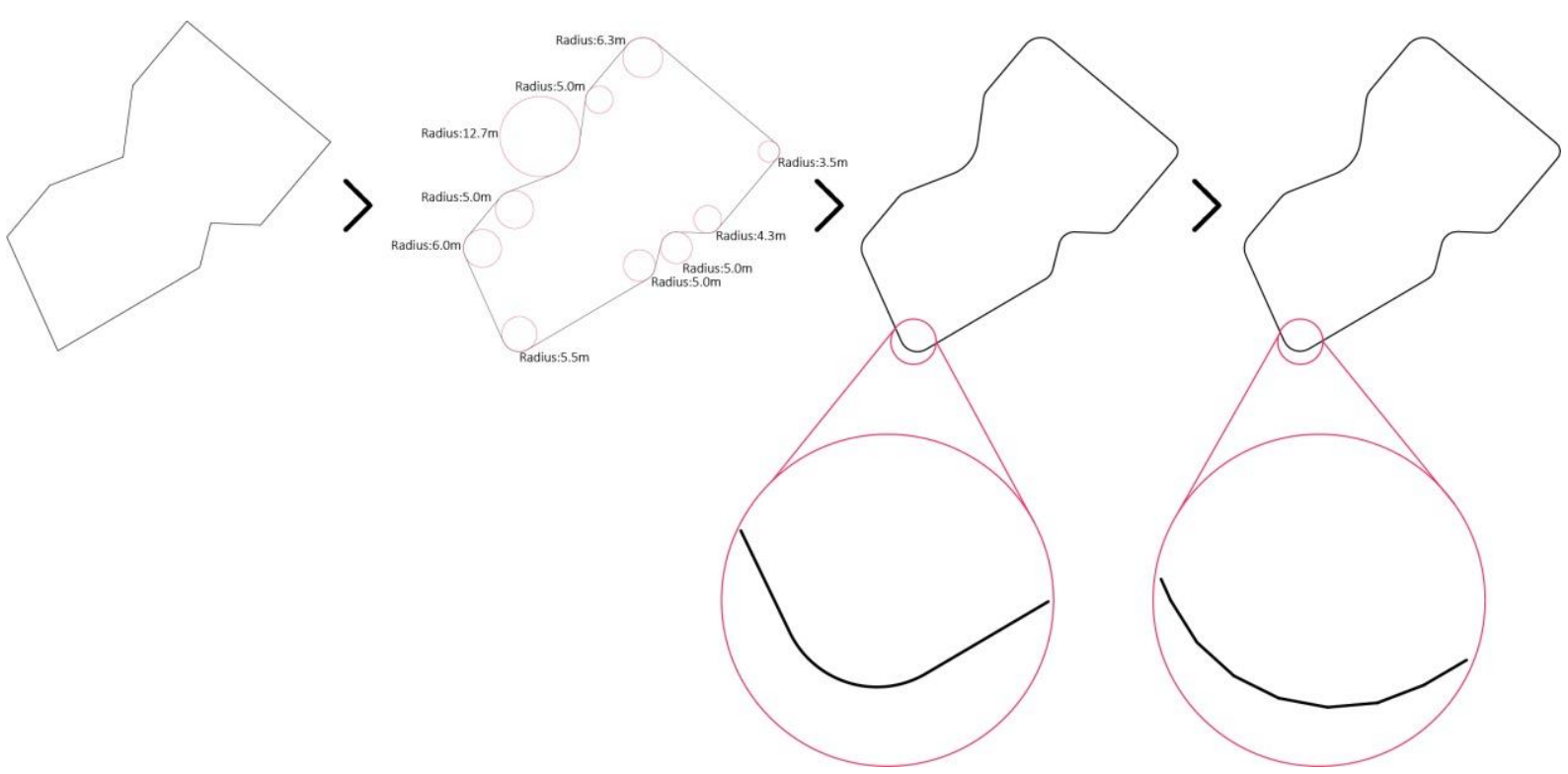

Figure 10: Design process of the glass surface of the façade. Source: Authors.

As a consequence of this design principal, façade surfaces divided into 33 zones according to geometric similarities to planar and single curved surfaces and then paneled into quadrilateral meshes (Figure 9).

Due to the economic reasons, for the glass part of the façade, arc curves were defined as the connection of straight lines. In figure 10, the design steps of the glass surface of the façade are illustrated. As well as GRC surfaces of the façade, glass surface was designed as a linkage of the various radius of arcs and lengths of lines. For the detail drawing phase, arc geometry was defined by straight lines. The closed curve of the glass surface was divided into $1.5 \mathrm{~m}$ length within different heights due to the freeform surface geometry (Figure 10).

Prefabricated glass panels are transferred to the construction site for the assembly (Figure 11). The joint spacings of the glass panels vertically continue through the GFRC panels. Both vertically and horizontally paneled entire joint spacings are designed to come one after another as a whole through the façade.
It is important to define the paneling of the façade surface based on joint detail, material selection, and connection details. As freeform designs became more popular in architecture environment, fabrication technic and process also gain importance among architects and entire collaborators. In order to reach the resemblance between intended designs and the end product, architects should systematically define manufacturing process starting from the early design phase, particularly the paneling phase of the surface. Within this context, paneling of the façade surface was done in the architecture office within a close collaboration between other disciplines under the aegis of "BDS" consulting.

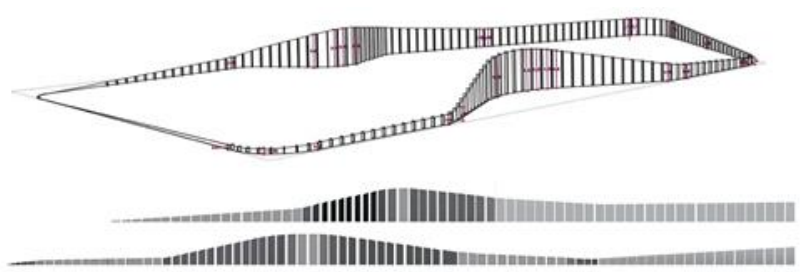

Figure 11: Glass fin supported façade panels. Source: Authors. 


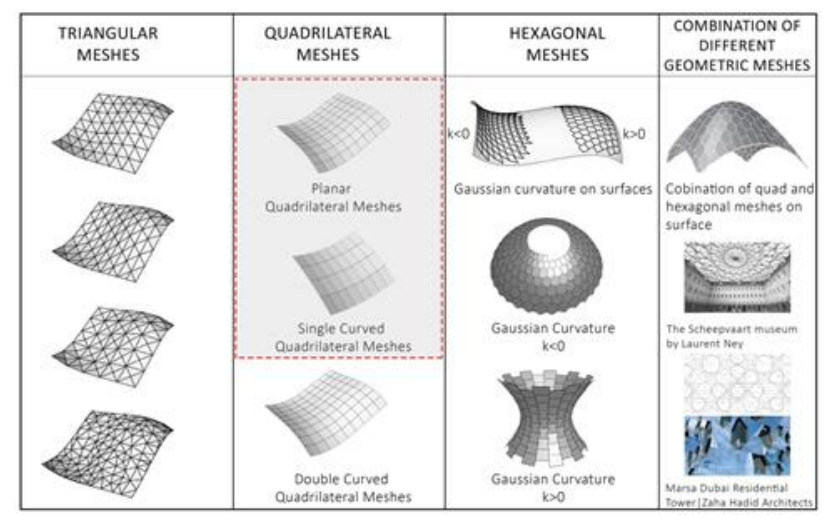

Figure 12: Façade surface paneling AFA Cultural Center. Source: Authors.

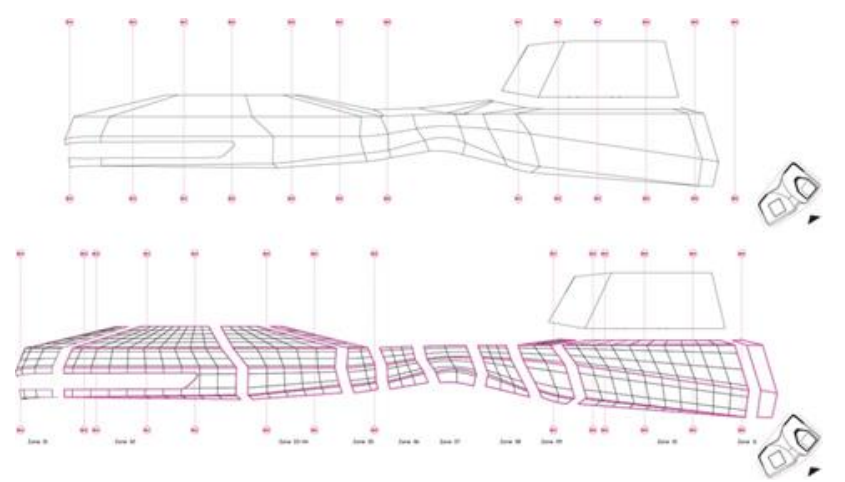

Figure 13: Façade surface paneling process. Source: Authors.

The façade surface was paneled as quadrilateral meshes while following the vertical joint spacing of the glass façade (Figure 12). The zone one was vertically paneled following the vertical joint spacing of the glass façade. The horizontal paneling of the surface was done depending on the transportation limit and assembly process of the GRC panels as $3 \mathrm{~m} \times 3 \mathrm{~m}$. While paneling the surface by quadrilateral meshes, the previous discretized zone was used as a reference to the next zone during the paneling process. Every panel has named with dimensions in the $2 \mathrm{D}$ documents as well as the $3 \mathrm{D}$ environment. Thus, in case of damage to the panel or changes on the panel, we can easily identify the panel during the construction phase or after construction (Figure 13).

Façade divided into thirty-three zones according to

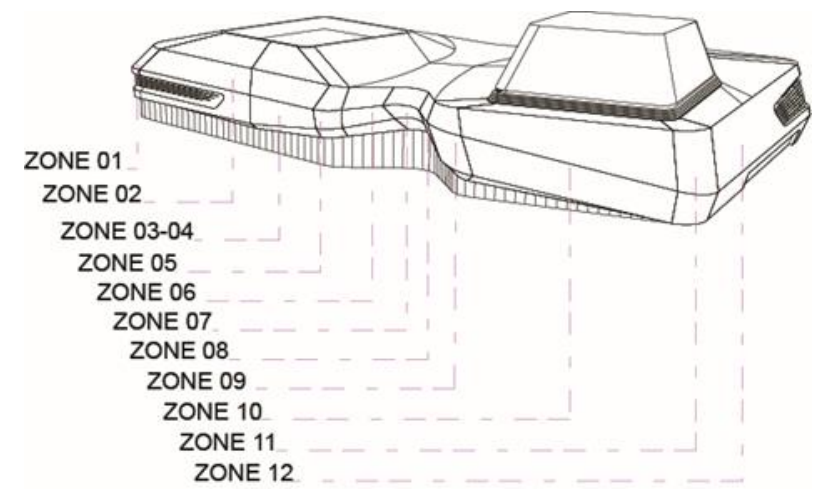

Figure 14: Façade surface zones of AFA Cultural Center. Source: Authors.

geometric properties (Figure 14). The entire zones were discretized independent of each other while whole joint spacing comes one after another each other as a whole through the façade. All the vertical and horizontal openjoint gaps are continued like a closed curve on the façade form.

Whole discretized surfaces were unrolled and written to the excel documents as a bill of quantities. Every panel has named with dimensions in the $2 \mathrm{D}$ documents as well as the 3D environment (Figure 15). Thus, in case of damage to panel or changes on the panel, we can easily be identified by the panel during the construction phase or after construction.

\section{CONCLUSION}

The aim of the paper is to provide a guideline to the architects who will design freeform architectural geometries while illustrating the importance of a systematic design approach for architectural design as in product design. As a consequence of the technological developments, architectural design, and manufacturing process are turned into a file to a factory process. Within the scope of the case of AFA Cultural Center project, it was realized that rationalization and construction of these freeform designs are especially hard with the conventional building methods. With the help of CAD and CAM tools, revision time in the case of the AFA Cultural Center was shorter than in any conventionally designed buildings. In the short time, revisions were done by changing inputs of
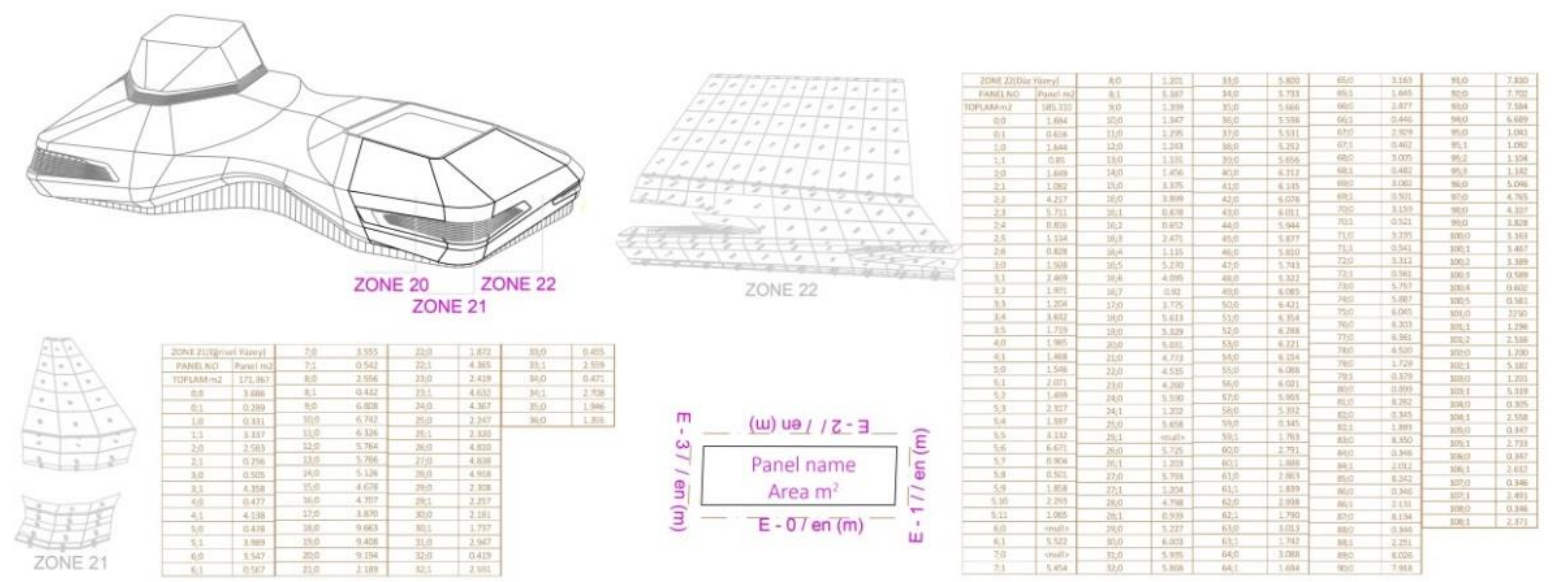

Figure 15: Façade surface paneling details. Source: Authors. 
the design. And also, a systematic design approach enabled architects to have control over the entire process and effectively communicate with whole stakeholders of the projects.

\section{REFERENCES}

Council, D. (2007). Eleven lessons: Managing design in eleven global companies-desk research report. Design Council.

Knaack, U., Klein, T., Bilow, M., \& Auer, T. (2014). Façades: principles of construction: Birkhäuser.

Mostafavi, M., \& Leatherbarrow, D. (2002). Surface Architecture. Cambridge (Mass.). 